Open Access

\title{
Computerized tomography based tumor- thickness measurement is useful to predict postoperative pathological tumor thickness in oral tongue squamous cell carcinoma
}

\author{
J. Madana ${ }^{*}$, Frederick Laliberté, Grégoire B. Morand, Deeke Yolmo, Martin J. Black, Alex M. Mlynarek \\ and Michael P. Hier
}

\begin{abstract}
Background: Tumor thickness has been shown in oral tongue squamous cell carcinoma (OTSCC) to be a predictor of cervical metastasis. The postoperative histological measurement is certainly the most accurate, but it would be of clinical interest to gain this information prior to treatment planning. This retrospective study aimed to compare the tumor thickness measurement between preoperative, CT scan, and surgical specimens
\end{abstract}

Methods: We retrospectively included 116 OTSCC patients between 2001 and 2013. Thickness was measured on computer tomography imaging and again surgical specimens.

Results: The median age was 66 years. $62.8 \%$ of patients were smokers with a mean of 31.4 pack-years. Positive nodal disease was reported in $41.2 \%$. Mean follow-up time was 33.1 months. The correlation between CT scan-based tumor thickness and surgical specimens based thickness was significant (Spearman rho $=0.755, P<0.001$ ).

Conclusion: Tumor thickness assessed by CT scan may provide an accurate estimation of true thickness and can be used in treatment planning.

Keywords: Tumor thickness, Oral tongue, Computerized tomography, Measurement, Postoperative

\section{Introduction}

Oral squamous cell cancer (OSCC) accounts for approximately $2.5 \%$ of all cancers in the United States and are primarily associated with chronic consumption of alcohol and tobacco [1]. OTSCC are particular in their high propensity to metastasize given the rich lymphatic drainage among most of the anatomic subsites. This is clinically relevant as cervical lymph node metastasis are thought to be the single most important prognostic factor in head and neck carcinoma, with certain studies reporting an associated 5-fold increase in mortality [2].

One issue is that a high proportion of OSCC present with occult cervical metastasis. The literature indeed shows that they are present in $18 \%$ to $53 \%$ of cT1-2 N0 oral cavity cancers [2-5]. The prediction and therapeutic assessment of occult metastasis is important, as nodal

\footnotetext{
*Correspondence: maddyy@gmail.com

Department of Otolaryngology-Head and Neck Surgery, Sir Mortimer B. Davis-Jewish General Hospital, McGill University, 3755 Côte Ste-Catherine Road, Montreal, QC, CanadaH3T 1E2
}

metastasis that become clinically apparent have been ective neck dissections. This approach will be useful for the proportion of patients with occult metastasis but Analogous to melanoma [8], tumor thickness is now increasingly used in OSCC.to predict lymph node metastasis [9-13]. While the gold standard to measure tumor thickness is ultimately postoperative tumor thickness assessed on definitive pathology, it would be useful to establish a method to evaluate tumor thickness preoperatively, thus avoiding two-step surgery. Different modalities, allowing preoperative measurement of tumor thickness are being evaluated with conflicting results.

Our retrospective study evaluates the accuracy of computer tomography (CT scan) in predicting histological tumor thickness. 


\section{Materials and methods Patient population}

Records of patients who presented to the Jewish General Hospital with a new diagnosis of oral tongue SCC during the period of January 2001-January 2013 were retrieved $(n=116)$. Information was collected retrospectively on patients' characteristics (i.e. age, gender, smoking and drinking habits), clinical and pathological tumor characteristics (i.e. TNM staging, tumor thickness according to CT scan, histological postoperative tumor depth/thickness). CT scan reports were reviewed for all patients to collect the tumor thickness data. Likewise the final postoperative reports (signed out by Head and Neck Pathologists) were reviewed to obtain data regarding surgical tumor thickness.

\section{Statistical analysis}

Binary variables were associated in contingency tables using the two-sided Fisher exact test. Odds ratio (OR) and $95 \%$ confidence interval $(95 \% \mathrm{CI})$ were calculated also using twoby-two tables, according to the Mantel-Haenszel method. A $P$ value lower than 0.05 was considered to indicate statistical significance. Non-parametric Spearman method was used to assess correlation between numeric scaled variables. Statistical analyses were performed using SPSS ${ }^{\circ} 21.0 .0$ software (IBM $\odot$, Armonk, NY, USA).

\section{Results}

\section{Study population}

In total, 116 patients were included in the study. The median age was 66 years (range 28-92). There were 50 females (43.1\%) and 66 (66.9 \%) males. Alcohol consumption was reported in $42.2 \%$ of the cases. Regarding smoking habits, $37.2 \%$ of patients were never smokers, $35.1 \%$ former smokers and $27.7 \%$ current smokers. The mean reported cumulative cigarette consumption was 31.4 ( \pm S.E. 2.4$)$ pack years. Pathological positive nodal disease was reported in $41.2 \%$. Clinical stage I, II, III and IV were reported in $29.8 \%, 16.7 \%, 15.8 \%$ and $32.5 \%$, respectively. Stage 0, corresponding to in situ tumor was reported in $5.3 \%$. Mean follow-up time was 33.1 months $( \pm$ S.E. 3.7$)$. Clinically negative necks turned out pathologically positive in $23.4 \%$ patients. Locoregional recurrence was reported in $22.6 \%$ of the patients, while $13.6 \%$ of them suffered disease-specific death. Overall, $18.1 \%$ died of any cause in this cohort.

\section{CT tumor thickness versus postoperative tumor thickness} The mean postoperative final pathological tumor thickness was $11.60 \mathrm{~mm}$ while the mean CT tumor thickness was $12.88 \mathrm{~mm}$. The correlation between CT thickness and postoperative thickness was highly significant (Spearman rho $=0.755, P<0.001$ ) (Fig. 1). Figure 2 shows the box and whisker box plot for CT scan based tumor thickness and postoperative tumor thickness.

\section{Discussion}

In order to better stratify OSCC patients according to their occult cervical metastasis risk, growing evidence supports the use of tumor thickness [14]. It would be very useful to establish a reliable method to predict

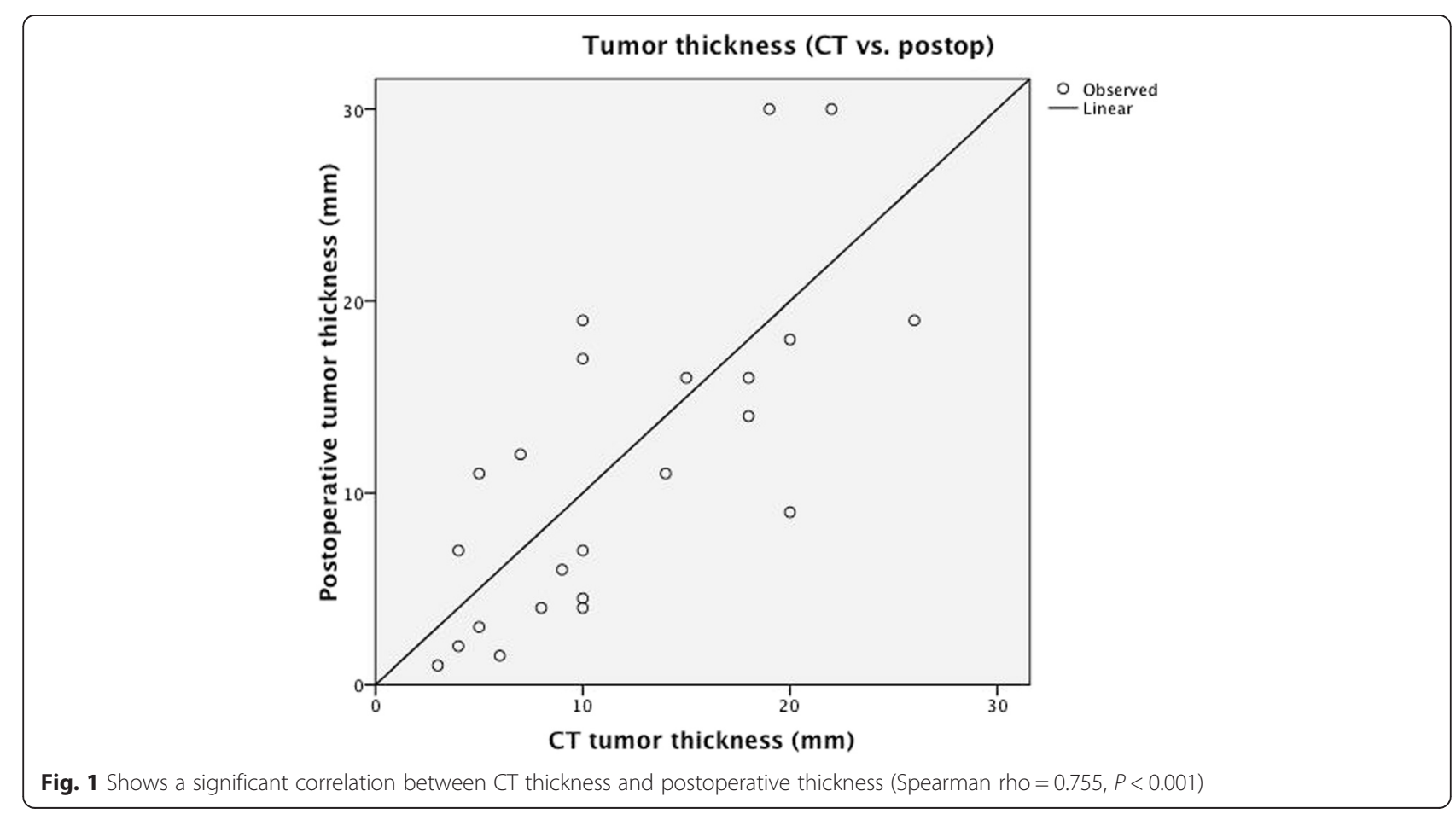




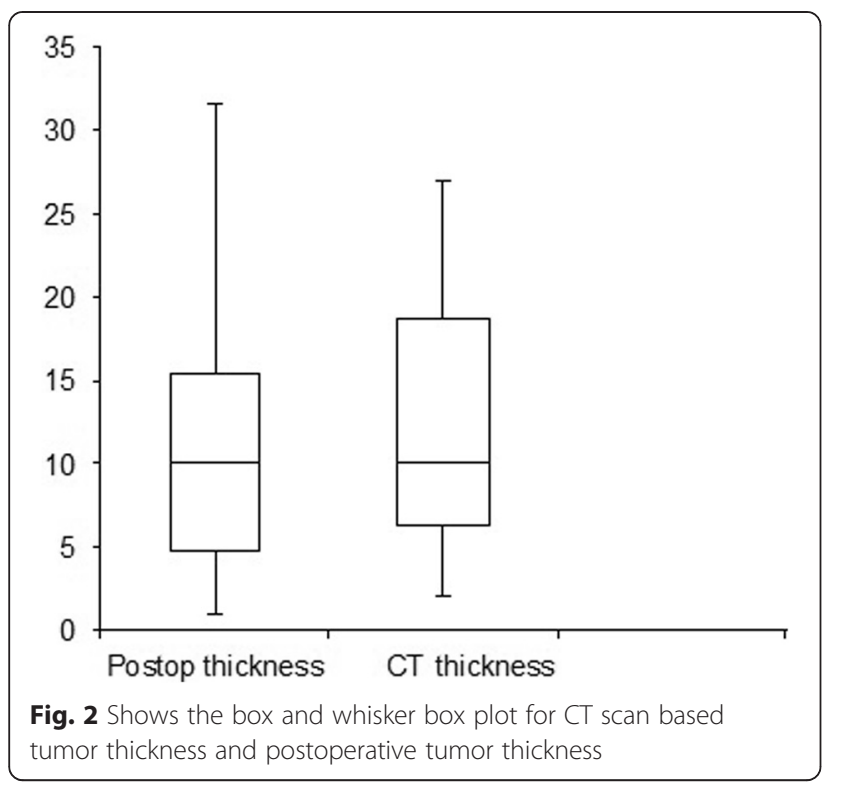

tumor thickness preoperatively, thus avoiding two-step surgery.

While there are currently no established methods of assessing tumor thickness pre-operatively, three main options are currently being investigated: preoperative biopsy, intraoral ultrasonography, and CT imaging.

To our knowledge, there is very limited data on the accuracy of preoperative tumor biopsy to predict histological tumor thickness. We previously conducted an unpublished retrospective study and compared tumor thickness estimated from preoperative tumor biopsy with the final postoperative pathologic measurement. We demonstrated a lack of significant correlation between the two measurements in thicker tumors and concluded that tumor thickness should not be reported in biopsy reports, as especially thicker tumors were at risk to harbour nodal metastasis.

There is emerging evidence that intraoral ultrasonography may accurately predict histological tumor thickness in OSCC. Shintani et al. were among the first to demonstrate this correlation in tongue carcinoma by comparing preoperative ultrasound estimation of tumor thickness with measurements obtained from postoperative histological sections [15]. Since then, many authors have published similar results with other sub sites (i.e. floor of mouth) while also showing direct correlation between ultrasound tumor thickness and neck metastasis $[16,17]$. Limitations to intraoral ultrasonography include tenderness, trismus, or anatomic location hindering adequate ultrasound probe placement. Furthermore, discordances between pathological and ultrasound derived tumor thickness have been recorded in thicker tumors (i.e. $>20 \mathrm{~mm}$ ) and is explained by transducer limitation as well as tissue shrinkage secondary to histological processing $[15,16]$.
The use of imaging in assessing tumor thickness has not being discussed critically in the literature. Park et al. performed a retrospective study to evaluate the accuracy of MRI in measuring the invasion depth of different oral cavity cancers [18]. The authors calculated Pearson's correlation coefficient for histologic and imaging invasion depths in oral tongue, tongue base, and tonsil cancers of $0.949,0.941$, and 0.578 , respectively. Their study also demonstrated a direct correlation between radiologic invasion depth and lymph node metastasis in oral tongue and tongue base cancers with calculated invasion depth cut-off values of $9.5 \mathrm{~mm}$ and $14.5 \mathrm{~mm}$, respectively. Interestingly, the mean invasion depth measured from histologic specimens was less than when measured by imaging. This is likely due to shrinking of tissue following resection and processing, which has been previously reported in the literature [19]. Lam et al. performed a similar study and validated the accuracy of imaging in estimating tumor thickness in oral tongue cancer [14].

On the other hand, Lwin et al. analyzed MRI imaging and histopathological reports of 102 consecutive OSCC cases and concluded that radiological staging of the neck or tumor thickness could not safely determine the need for neck dissection [20]. Indeed, the authors found no valid radiological tumor thickness threshold that could be used clinically to predict nodal involvement. Moreover, they reported a total of 11 tumors, with sizes varying from $2 \mathrm{~mm}$ to $24 \mathrm{~mm}$, which were undetectable on radiology.

Our study results showed a significant correlation between postoperative final pathological tumor thickness and CT based tumor thickness. While MRI may be superior to $\mathrm{CT}$ in the evaluation of soft tissue lesions, our results may support the use of $\mathrm{CT}$ in measuring tumor thickness. This may be relevant as CT scanning is faster and usually more available than MRI.

In conclusion, this study supports a role for CT scan in determining tumor thickness in OTSCC.

\section{Competing interests}

The authors declare that they have no competing interests.

\section{Authors' contributions}

Original idea by MJ and MPH. MJ designed and conducted the study and gathered the data with FL. GM \& LB performed statistical analysis, figures, which was reviewed and approved by MJ, MPH, MJB and AM. All authors read and approved the final manuscript.

\section{Acknowledgment}

GBM is supported by the Swiss Cancer League, Effingerstrasse 40, 3001 Bern, Switzerland (BIL KFS-3002-08-2012). No funding involved.

Received: 29 January 2015 Accepted: 31 August 2015

Published online: 16 November 2015

\section{Reference}

1. Oral cancer incidence statistics. Cancer Research UK. 16 Mar. 2012. 11 Apr. 2014 http://www.cancerresearchuk.org/cancer-info/cancerstats/types/oral/ incidence/. 
2. Ganly I, Patel S, Shah J. Early stage squamous cell cancer of the oral tongue-clinicopathologic features affecting outcome. Cancer. 2012;118(1):101-11.

3. Ross GL, Soutar DS, MacDonald DG, Shoaib T, Camilleri IG, Robertson AG Improved staging of cervical metastases in clinically node-negative patients with head and neck squamous cell carcinoma. Ann Surg Oncol. 2004;11(2):213-8.

4. Khafif RA, Gelbfish GA, Tepper P, Attie JN. Elective radical neck dissection in epidermoid cancer of the head and neck. A retrospective analysis of 853 cases of mouth, pharynx, and larynx cancer. Cancer. 1991;67(1):67-71.

5. Leusink FK, van ES RJ, de Bree R, Baatenburg de Jong RJ, van Hooff SR, Holstege FC, et al. Novel diagnostic modalities for assessment of the clinically node-negative neck in oral squamous-cell carcinoma. Lancet Oncol. 2012;13(12):e554-561.

6. Monroe MM, Gross ND. Evidence-based practice: management of the clinical node-negative neck in early-stage oral cavity squamous cell carcinoma. Otolaryngol Clin North Am. 2012;45(5):1181-93.

7. Andersen PE, Cambronero E, Shaha AR, Shah JP. The extent of neck disease after regional failure during observation of the NO neck. Am J Surg. 1996;172(6):689-91.

8. Breslow A. Thickness, cross-sectional areas and depth of invasion in the prognosis of cutaneous melanoma. Ann Surg. 1970;172(5):902-8.

9. Mohit-Tabatabai MA, Sobel HJ, Rush BF, Mashberg A. Relation of thickness of floor of mouth stage I and II cancers to regional metastasis. Am J Surg. 1986;152(4):351-3.

10. Al-Rajhi N, Khafaga Y, El-Husseiny J, Saleem M, Mourad W, Al-Otieschan A, et al. Early stage carcinoma of oral tongue: prognostic factors for local control and survival. Oral Oncol. 2000:36(6):508-14.

11. Moore C, Kuhns JG, Greenberg RA. Thickness as prognostic aid in upper aerodigestive tract cancer. Archives of Surgery. 1986;121(12):1410-4.

12. Spiro RH, Huvos AG, Wong GY, Spiro JD, Gnecco CA, Strong EW. Predictive value of tumor thickness in squamous carcinoma confined to the tongue and floor of the mouth. Am J Surg. 1986;152(4):345-50.

13. Nathanson A, Agren K, Biorklund A, Lind MG, Andreason L, Anniko M, et al. Evaluation of some prognostic factors in small squamous cell carcinoma of the mobile tongue: a multicenter study in Sweden. Head Neck. 1989:11(5):387-92.

14. Lam P, Au-Yeung KM, Cheng PW, Wei WI, Yuen AP, Trendell-Smith N, et al. Correlating MRI and histologic tumor thickness in the assessment of oral tongue cancer. AJR Am J Roentgenol. 2004;182(3):803-8.

15. Shintani S, Nakayama B, Matsuura H, Hasegawa Y. Intraoral ultrasonography is useful to evaluate tumor thickness in tongue carcinoma. Am J Surg. 1997;173(4):345-7

16. Mark Taylor S, Drover C, Maceachern R, Bullock M, Hart R, Psooy B, et al. Is preoperative ultrasonography accurate in measuring tumor thickness and predicting the incidence of cervical metastasis in oral cancer? Oral Oncol. 2010;46(1):38-41.

17. Lodder WL, Teertstra HJ, Tan IB, Pameijer FA, Smeele LE, van Velthuysen ML, et al. Tumour thickness in oral cancer using an intra-oral ultrasound probe. Eur Radiol. 2011;21(1):98-106.

18. Park JO, Jung SL, Joo YH, Jung CK, Cho KJ, Kim MS. Diagnostic accuracy of magnetic resonance imaging (MRI) in the assessment of tumor invasion depth in oral/oropharyngeal cancer. Oral Oncol. 2011;47(5):381-6.

19. Mistry RC, Qureshi SS, Kumaran C. Post-resection mucosal margin shrinkage in oral cancer: quantification and significance. J Surg Oncol. 2005;91(2):131-3.

20. Lwin CT, Hanlon R, Lowe D, Brown JS, Woolgar JA, Triantafyllou A, et al. Accuracy of MRI in prediction of tumour thickness and nodal stage in oral squamous cell carcinoma. Oral Oncol. 2012;48(2):149-54.

\section{Submit your next manuscript to BioMed Central and take full advantage of:}

- Convenient online submission

- Thorough peer review

- No space constraints or color figure charges

- Immediate publication on acceptance

- Inclusion in PubMed, CAS, Scopus and Google Scholar

- Research which is freely available for redistribution

Submit your manuscript at www.biomedcentral.com/submit 